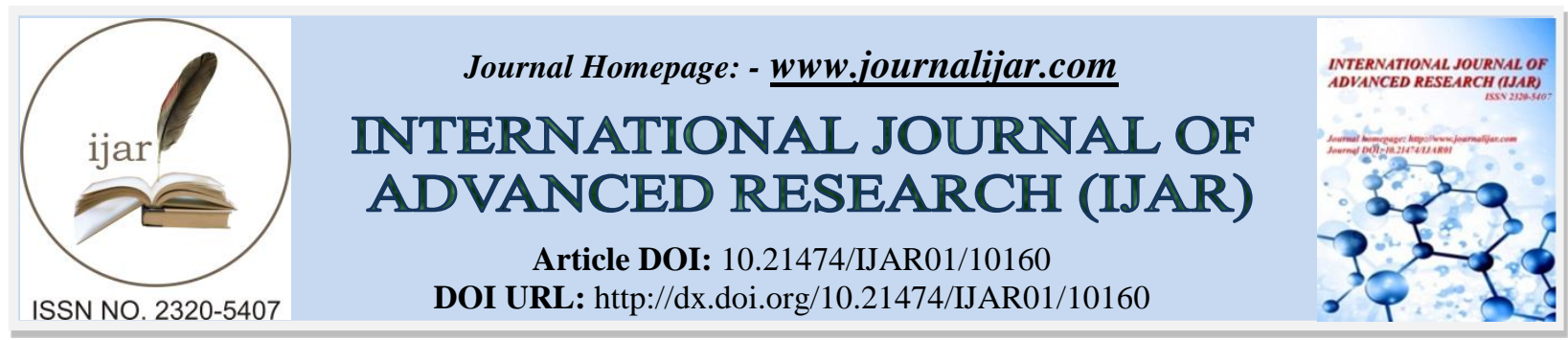

RESEARCH ARTICLE

\title{
AUGMENTED VIRTUAL REALITY IN EDUCATION AND THE FIELD OF MEDICINE FOR GLOBAL
} IMPACT.

\author{
Mayowa P. Oleseni ${ }^{1}$, David B. Olawade ${ }^{2}$, Temitope D. Afolalu ${ }^{3}$, Oluwaseun E. Olatoye ${ }^{3}$ and Iyanuoluwa G. \\ Akinwalere ${ }^{4}$. \\ 1. Department of Medical Science Afe Babalola University, Ado-Ekiti, Nigeria. \\ 2. Department of Environmental Health Sciences, University of Ibadan, Ibadan, Nigeria \\ 3. Department of Nursing Science Afe Babalola University, Ado-Ekiti, Nigeria. \\ 4. Department of Nursing Science Northumbria University, Newcastle UK.
}

\section{Manuscript Info}

Manuscript History

Received: 03 October 2019

Final Accepted: 05 November 2019

Published: December 2019

Key words:-

Augmented Virtual Reality, Real-Time, Global Impact, 3D virtual.

\begin{abstract}
Innovation in training can impact understudies to adapt effectively and can spur them, prompting a viable procedure of learning. Past research has recognised the issue that technology could make an underlying learning process, particularly if the innovation utilised does not advance basic reasoning. Since the approach and advancement of Augmented Virtual Reality (AVR), it has been appeared to have great potential in making the learning procedure more intriguing, dynamic, successful and practical. This is because AVR enables users to interact with real-time and virtual applications and presents the subjective experiences to the user. Also, the synergism of AVR with education has attracted attention by researchers because of its ability to allow students to participate in experiences. The use of AR in the field of medicine also paves the way for innovations that can turn medicine around and increase the hope of individuals that come with challenging medical conditions that AVR will aid in addressing either by way of diagnosing, treating, or ensuring palliative measures to prolong life. In this study, it shows that overall, AVR technologies have positive potential and advantages that can be adapted in both education and medicine. Some of the limitations of AVR are discussed as well as possibilities of the future of AVR in our world today and for the generations to come.
\end{abstract}

Copy Right, IJAR, 2019, All rights reserved.

\section{Introduction:-}

Augmented Virtual Reality (AVR) alludes to a system that consolidates a whole world and virtual items which are created digital content by a PC and plans to convey an upgraded and bound together perspective on the planet. In this manner, AR can enable the client to see 3D virtual articles superimposed upon this present reality. The term was instituted in 1990 by Professor Tom Caudell. The essential target is to give a rich, broad media experience. AVR consolidates this current reality we at present live in with virtual components. The blend of the two is hypothetically intended to improve each other. Augmented reality has been in use for many years longer than a great many people figure it out. It has been around for several decades. Be that as it may, the ongoing advances in augmented reality and the development in interests in the field give proof that AR could before long be the following colossal business ware $[1,2]$. 
In 1968, a Harvard educator and PC researcher by the name of Ivan Sutherland invented what he called The Sword of Damocles. He developed this first kind of augmented reality gadget with his understudy, Bob Sproull. The Sword of Damocles included a head-mounted showcase that dangled from the roof. The client would encounter PC designs, which made that person feel just as they were in a substitute reality. This innovation might be viewed as nearer to computer-generated truth than augmented reality. One of the next considerable advancements in AR was in 1974 by Myron Krueger [2,3]. The undertaking was called Video place, which consolidated a projection framework and camcorders that created shadows on the screen. This setup made the client feel just as they were in an intuitive situation.

In 1990, a Boeing scientist named Tom Caudell authored the expression "Augmented Virtual Reality". The USAF Armstrong's Research Lab head by Louis Rosenburg made the main genuine operational AR framework, Virtual Fixtures in 1992. A mechanical framework places data on top of the specialist's workplace to help with proficiency [3]. This framework could be thought of as an early form of what most AVR frameworks as of now do today. In 1994, AR technology was made. "Dancing in Cyberspace" introduced Julie Martin created trapeze artists moving in and around virtual items in front of an audience as a bit of craftsmanship. In 1998, sports vision utilised the first- and Ten-line PC framework. This framework demonstrated the first virtual yellow initially down marker amid a live NFL diversion. A variety of this virtual first-down marker is presently a standard in all broadcast football matchups today and is a significant piece of the AVR history [4,5]. In 1999, NASA utilised a half breed engineered vision framework that coordinated augmented reality in their X-38 rocket. The enlarged reality innovation was used to help improve route amid their dry runs. A vital headway in the enlarged reality innovation occurred in 2000 when Hirokazu Kato made and discharged programming called AVR ToolKit. Through this product, one could catch certifiable activities and consolidate it with the communications of virtual items. Using a camera and the Internet, clients experience this AVR [5].

In the same way as other of these creations from the past, this vigorously affected what we suffer today in all glimmer-based AR applications. In 2003, the NFL utilised the mainstream Skycam, which was being used for ethereal perspectives on the field to embed the virtual first-down marker. In 2009, Esquire magazine, in a joint effort with Robert Downey Jr., utilises AR in their print media. By using their product on one's PC to examine the scanner tag on the magazine, the peruses can encounter AR content. In this equivalent year, ARToolKit makes augmented reality accessible to Internet programs. Augmented reality has progressed significantly since its initial origination, and the headways in the previous five years have been considering all the more encouraging.

\section{Modern Day Augmented Reality:-}

In 2013, Volkswagen utilised augmented reality as their vehicle manuals. The utilisation of the MARTA application through the iPad can enable clients to see the inside functions of the vehicle, so the administration mechanics recognise what they are managing. The MARTA application can likewise indicate the following guidelines to assist mechanics with the tasks they are dealing with a per period. It can even help with supplanting parts. It can also be as explicit as which bearing the pieces ought to confront. The MARTA application can be utilised for progressively restorative ventures too, including perceiving how extraordinary shading paint occupations can look on vehicle [6]. In 2014, Google Glass was uncovered and was made accessible to customers. The Google Glass was not as capable as engineers trusted it would be, yet it showed the capability of what wearable AR could be. The second emphasis as of now is by all accounts, additionally encouraging and increasingly valuable. Rather than utilising the Glass to look through online networking and different applications, assembly line labourers are using the innovation to help with regular work. It helps walk the labourers through their day by day errands and be increasingly gainful and productive [7,8]. In 2016, Microsoft presented the following cycle of wearable augmented reality. The HoloLens is by all accounts everything that the Google glass needed to be, yet unquestionably not as watchful and wearable in regular day to day existence and is without a doubt progressively costly. The innovation headway between the two is undeniable. However, the value scope of $\$ 3000$ and $\$ 5000$ are out of a great many people's financial plans. Numerous individuals in the AR industry trust their time is here. AR experts believe they are going to cash in big in a field that is developing massively at a quick step [9,10]. Interests in augmented reality have likewise been on the uprising and appear to incline upward. This could speak to the need for this kind of innovation.

\section{Complex and Enhances Learning Process AVR in Education:-}

Augmented reality can be gainful for human services experts in two different ways - in the part of instruction and preparing, and the role of diagnostics and treatment giving access to continuous patient information. There is no 
uncertainty that understudies will comprehend the idea better when they will envision it as a rule. Mainly for the troublesome themes, understudies will get the opportunity to adapt rapidly with 3-dimensional model portrayals. AR learning gives a methodology towards discovering that makes fun and energy for understudies rendering them eager to learn. Hence, it works up to their inspiration to the learning procedure. In all actuality; AR animates better learning procedure that pushes them into a learning place where they wind up basic in dismembering new thoughts. This expands the innovative ability of understudies in the learning procedure. Toward the end, understudies become their creative and thinking capacity. Accordingly, it serves a positive effect on the understudies and keeps them locked in [11]. Innovation has progressed toward becoming a piece of instruction. Today, understudies depend more on technology for everything. This has added to the sluggishness seen among understudies. Sufficiently, AR applications in training cover the different slips by in instructive innovation. The intuitive models gave presents understudies access to expanded and improved learning exercises. With gadgets inside the reach of understudies, there are expanded learning exercises among understudy [13].

\section{Effect on student learning:-}

The utilisation of AR applications in education achieves increment in understudy cooperation in class. These models help better and abnormal state comprehension of subjects among understudies. The more understudies comprehend having better handles of issues, the more their cooperation. This is the precise outcome that AR applications in education will, in general, accomplish. These applications help understudies handle ideas quicker and simpler through the given models. This results in active class cooperation while expanding inspiration and interest in the learning procedure [13]. Understudies can get to educative and learning AR models through scanning. They spread a more extensive scope of points cutting crosswise over numerous subjects. Understudies get to educative sites from AR application structured by AR application improvement organisations. This many learning knowledge makes an active learning cycle. Hence, it causes them to improve and retain learning after some time. This is conceivable because of the dimension of interest that accompanies learning through AR. On the long run, AR leads to a guzzling state of learning and motivation in understudies.

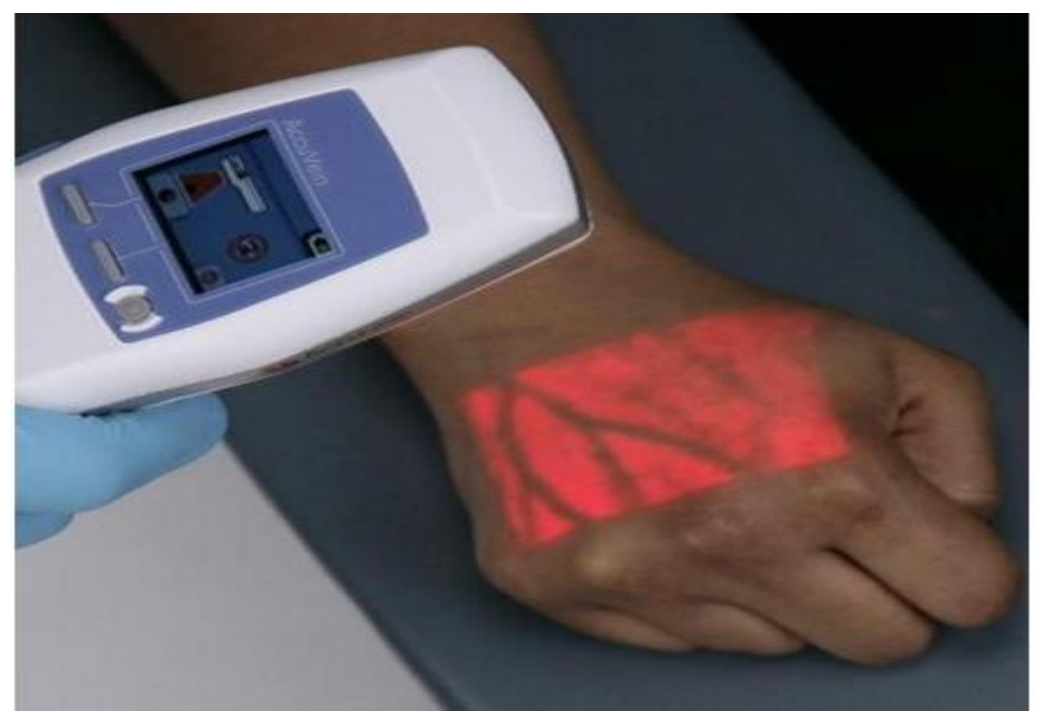

Plate 2.1:- AccuVein over the dorsum of the hand [10].

Consequently, it improves creative energy, which results in improved and expanded memory. The utilisation of AR in training will improve the mental and physical ability of understudies and give them the benefit to see, watch, and feel in the meantime while learning. Instead of being passive observers. Along these lines give them intuitive benefits to help upgrade their psychological and physical finesse, expand sensory development, and take the instructive learning procedure to another level. Medical students have dependably managed large measures of hypothesis behind surgeries, human life structures, and treatment conventions. What is more, presently, AR innovation enables them to imagine the information they acquire. For instance, AR applications can be utilised to overlay life systems information on a 3D human skeleton giving them a superior comprehension of how the human body functions [14]. 


\section{AVR in Medicine:-}

We can consider AR as a unique result of innovative improvements and the accessibility of information that has overflowed specialists as of late. AR can help specialists get to the most recent and most applicable data about their patients. Additionally, patients can likewise utilise AR for self-training and improving the nature of the treatment they get, which is probably the most critical instances of AR in medicine. One of the instances of augmented reality in medicine that is helpful for patients is NuEyes, a couple of hands-free, electronic shrewd glasses for the visually impaired. Noyes shrewd glasses enable individuals with low vision to see the things around them and perform regular assignments. They are a lightweight, remote, head-worn gadget which can be worked either with a remote controller or by utilising basic voice directions. As indicated by Forbes, NuEyes collaborates with a US significant social protection transporter, making these keen glasses progressively moderate for the visually impaired, as the insurer covers up to 50 per cent of the expense of the item [15]. Another AR-based item went for patients is Brain Power, the product created by the Massachusetts based start-up, which changes wearables, correctly, Google Glass, into neuro-assistive human-made brainpower frameworks to help individuals with brain-related difficulties, particularly autism. The product enables youngsters and grown-ups to build up their social aptitudes, language abilities, and social practices. Medical practitioners additionally can profit by AR innovation as there are AR-based items that are as of now utilised in social insurance. One of these items is AccuVein, which makes vein perception another standard of consideration. Numerous individuals fear blood tests and intravenous infusions since they are apprehensive the attendant will not almost certainly discover a thread the first run through and expanding the system and making it progressively excruciating. AccuVein is a projector gadget that utilises AR innovation to show a guide of the veins on the outside of the skin gradually. Data from the maker, emergency clinics and social insurance suppliers using these gadgets see a 39\% decrease in agony, a significant improvement of the infusion method first endeavour achievement rate is 3.5 occasions higher, and a \$352,498 yearly investment funds [16, 17].

AR in a medical procedure is likewise a demonstrated utilisation of this innovation. As indicated by the National Center for Biotechnology Information, the growth of reality has been utilised in a therapeutic process for a long time. This innovation is particularly crucial in neurosurgery, where the blend of radiographic output information obtained previously or in recent times is utilised to permit progressively precise and safe "neuronavigation". A case of AR in a medical procedure is the utilisation of Microsoft HoloLens as a guide for a spinal medical system. The Holographic Navigation Platform, created by Scopis, is utilised amid a surgery. This Holographic Navigation Platform acquires AR and mixed reality for efficiency in the room. Using the HoloLens, it demonstrates a mixed reality overlay (the details of the surgery plan) on the patient and is also very useful in the teaching of the newer generation of doctors. The engineers state that this product can "show you muddled tumour limits, help with embed positions and guide you along anatomical pathways". With regards to spinal medical procedure correctly, specialists can utilise this stage to follow pedicle fastens embedded the patient's body and change virtual presentations using signals to almost certainly observe essential numbers in their field-of-see. With regards to medical education, it helps students learn better, and not having the anatomy of the body as something abstract.

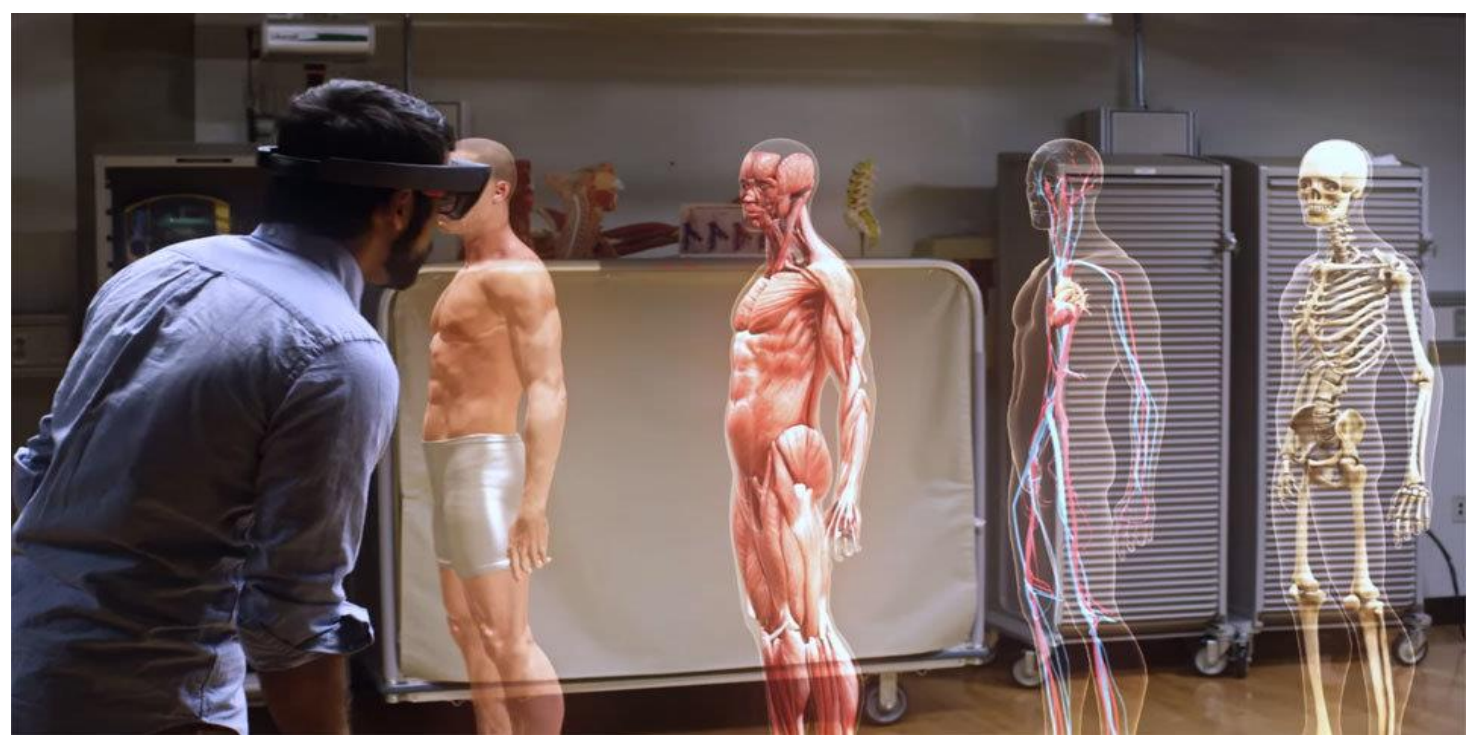

Plate 3.1:- Microsoft Hololens to advance the educational system and science [11]. 
AR is effectively utilised for diagnostics and treatment. This innovation is particularly valuable for negligibly intrusive medical procedures and increasingly complex systems. Quick access to constant patient information can spare lives as specialists utilise smart glasses, which picture this information. Here are some ways that AR is helping to transform the face of healthcare to tackle the challenges we encounter.

\section{Advantage of AVR in Medicine:-}

How to meet the medicinal needs of seven billion individuals when there are insufficient specialists to go around? Access to social insurance has generally been restricted by the accessibility of a specialist for every patient to see eye to eye - long lines in medical procedure sitting. The idea of telemedicine is evacuating these confinements by normalising the concept of restorative interviews over separation, using keen gadgets and the web. AVR has a crucial task to carry out in ensuring the nature of such interviews. This is mainly legal in the field of medical procedure. As opposed to just being about diagnostics, the Proximal application utilises AVR to enable total surgeries to be completed over some distance, with an expert using the AVR devices to direct and team up with a partner continuously [18]. The instantaneousness of this learning sharing methods ability can achieve more than envisaged, improving access to the medical procedure.

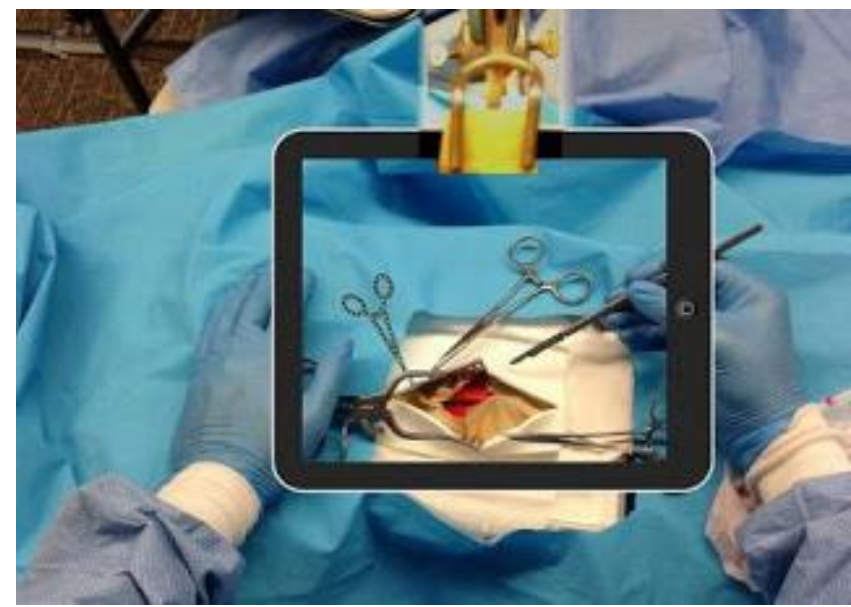

Plate 3.2:-Proximal- Long-distance Surgery software [12].

\section{Boosting training and Speeding up the adoption of new technology:-}

The solution of there not being sufficient medical practitioners to attend to patients is obviously, to prepare more. $\mathrm{AR}$ is as of now profoundly affecting medical training, with applications extending from 3D representations to give life into anatomical learning. A key advantage of $\mathrm{AR}$ as a learning device is that it makes an exceedingly captivating, vivid instructive experience which, by consolidating distinctive sensory information sources, helps maintenance and how well complex ideas can be grasped. Creative new advances which guarantee incredible advantages to a social insurance arrangement are consistently touching base available at a rate of bunches. In any case, one test the human services area faces is that there is frequently a slack between a promising innovation leaving its advanced stage and accomplishing far-reaching appropriation. Explanations behind this deferral incorporate things like the expenses of buying new tech, the time it takes to bring issues to light, and the need to coordinate new frameworks, from the establishment of preparing staff. Time lost to these postponements is time squandered in giving a possibly better administration to patients. AR can help. Rather than sitting tight for those allto-uncommon chances to exhibit new items up close and personal, applications like Proximal can enable sellers to achieve potential clients everywhere throughout the world whenever they like, offering inside and out showings. Following a purchase, AR can likewise be utilised to prepare staff remotely and to frame the premise of long-haul aftercare administrations.

Assisting practice and Empowering patients of AR:-

AR is a very supportive apparatus in helping therapeutic experts' complete daily assignments all the more precisely and effectively, from supporting analysis to helping with methods. Setting aside the remote coordinated effort part of Proximal, the AR instruments it gives are valuable in their very own privilege for a specialist in a theatre. The application enables us to do things like undertaking anatomical cross areas onto a patient or show 3D representations 
of internal organs, so the specialist gets a 'transparent' view as they plan procedures. Related applications incorporate AccuVein, an AR device which enables experts to find veins for cannulation. Future employment of AR may include electronic medical records being naturally shown on a gadget as specialist analyses or counsels with a patient, again featuring the instantaneousness that AR can convey to the practice of medicine. Another captivating pattern we see with the utilisation of AR in medical services is the advancement of uses that enable patients to assume an increasingly proactive job in their whole being. The Eye decides the application, for instance, is from one viewpoint another case of a 3D anatomical representation apparatus, this time exhibiting the structure of the eyeball. In any case, past that, it likewise offers visual representations of various eye conditions. Free on iPhone or iPad, clients can self-analyse by coordinating the reenactment to any challenges they are encountering in their vision, and the application at that point even offers a rundown of recommended eye authorities in their general vicinity to counsel further.

\section{Delivering treatment:-}

At last, AR is notwithstanding being utilised to treat patients in its very own right, particularly in connection to physiotherapy and physical recovery. The essential standard behind the utilisation of AR in this field is that computerised exhibitions can be explicitly mapped onto the movement's individuals execute as a significant aspect of their treatment. By watching themselves couple with the showing, they can refine their movements in like manner. This should be possible either with an entirely PC produced picture or with an advisor making the exhibition, as in the 'Ghostman' framework created by the University of Tasmania. The examination directed by analysts in Tasmania found that exceptional engine abilities grew a lot quicker utilising the AR device contrasted with customary up close and a personal showing. An AR device additionally offers the advantage of enabling treatment to be conveyed remotely. The use of augmented reality in the operating theatre could help surgeons to improve the outcome of reconstructive surgery for patients, as shown in Fig 4.

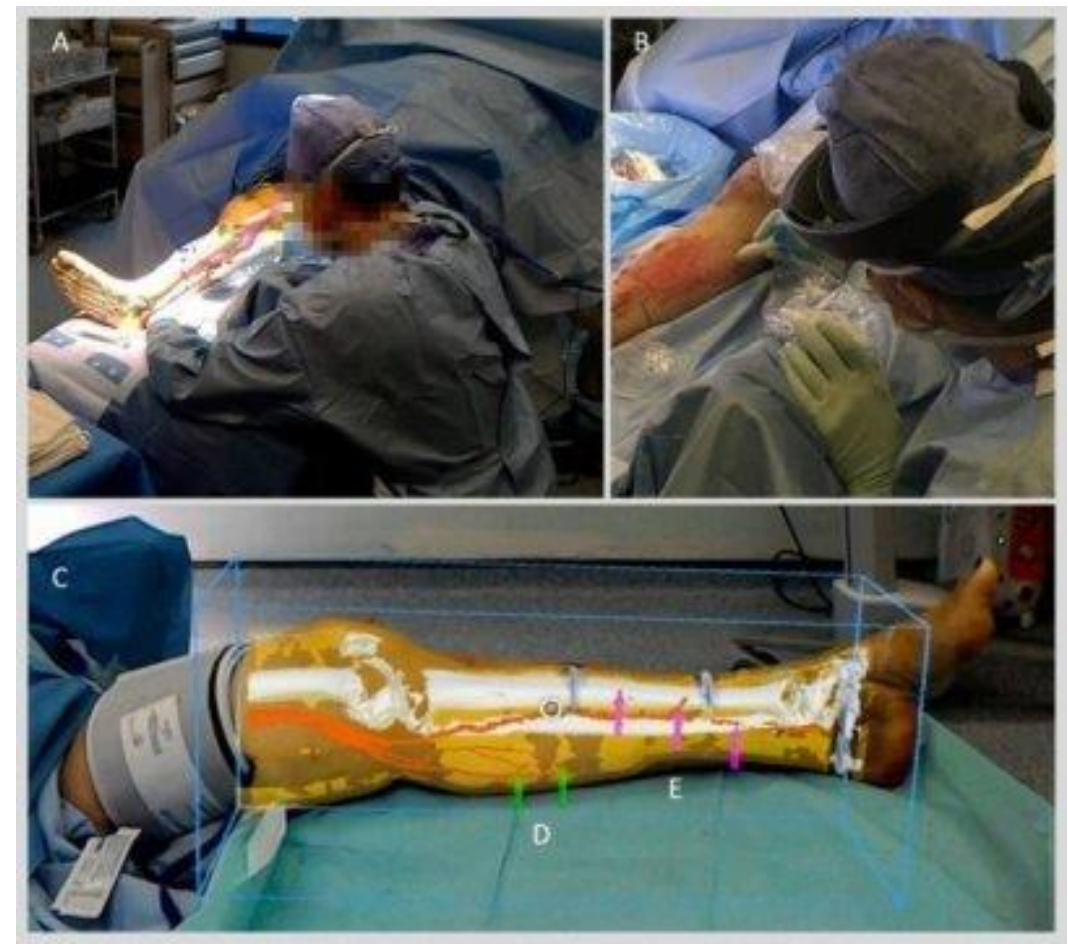

Plate 3.3:-Illustration of augmented reality in the operating theatre [13].

Hidden in the remarkable advancement in AR is the times of innovative work in computing, programming and the internet. The mix of such innovations will satisfy exponentially for all of us in the decades to come. The software can improve on in alignment and add markers to the patient when they scan; we prepare the same markers to use as additional reference points during the process. Some areas explore, and more improvements are needed, but the small case shows reconstructive surgery, it which is a valuable device in the operating room. 


\section{Result:-}

It opens understudies to the learning of the past, present, and future. Envision finding out insightful and educational concepts utilising models of past, current, and future occasions. Envision the benefit to using models that bring understudies into past incidents, also using the same models to find out about occurrences of things to come. Envision the advantages of consolidated information to take care of issues in our general public. Visiting the past, present, and future broadens one's mind.

Consequently, it improves comprehension and builds interest in the learning procedure. Today, AR application improvement for learning has changed the educational sector. Later, we will face a daily reality such that everybody can to a degree, be their very own specialists, which prompts better and increasingly productive therapeutic consideration. Clini Cloud, an Australian startup, made the world's first stethoscope for home use. There are situations where an expert is expected to establish a diagnosis. However, prompt AR telehealth devices will create the experience of heading off to a specialist considerably less cumbersome. Buying in drug and medicines through the smartphone, smart glass or a wearable gadget will likewise be prompt. Out of prescription. The smart device will naturally detect and send a warning to neighbourhood drug specialist or not long from now, printing its tablets through a $3 \mathrm{D}$ printer.

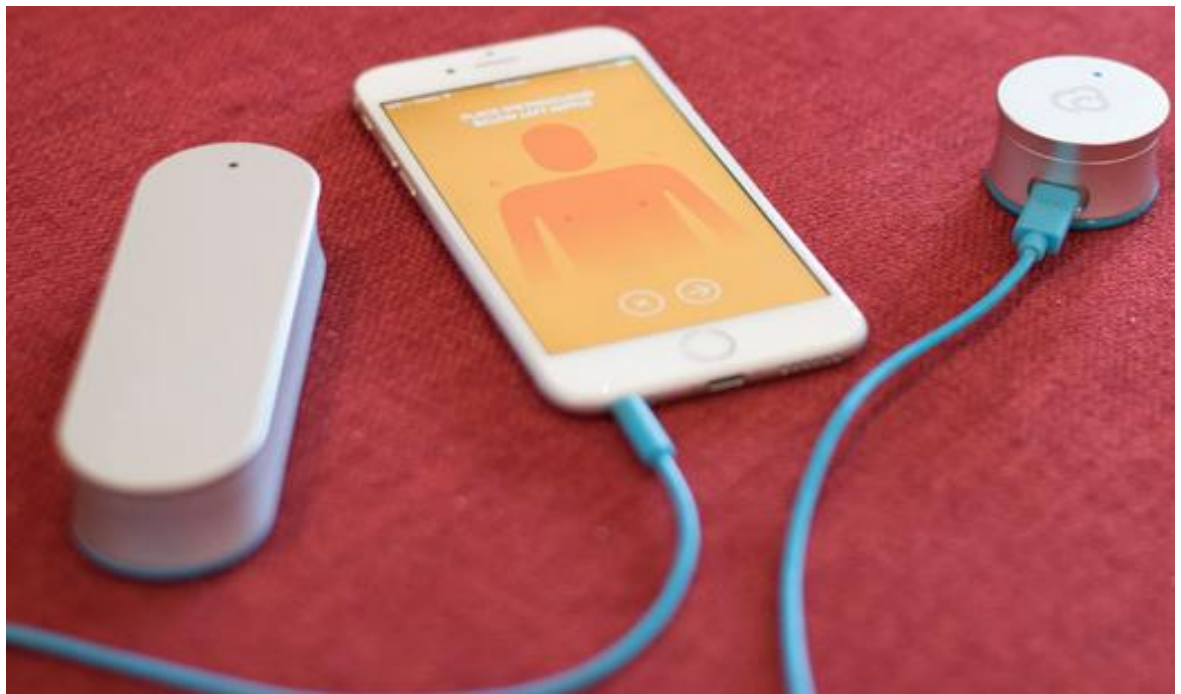

Plate 4.1:-Jeremy Dixon clinic loud connected stethoscope. Available from IPTC photo metadata [14].

Those in developing nations have the most to enjoy, in that advances can profit many lives through the sheer size of using smartphones and AR. In a general public where, therapeutic supplies are moderately significantly more costly, and specialists require an extended period to train because of weak quality institutions, such development in medicine will be a breakout opportunity towards higher expectations for everyday comforts. As laid out in Bill and Melinda Gate's 2017 letter to Warren Buffet, by decreasing the expenses of vaccinations and other wellbeing hindrances, the lives of 120 million children were spared since the 1990s [12-14]. If each smartphone or wearable gadget winds up standing in place for a doctor, social insurance costs will be immensely brought down, billions of lives will be spared, and our expectations for everyday comforts are increased. We ought to be, without any doubt, hopeful about our future. For many years, people have dependable and eventually figured out how to tackle complex issues, and the headway in AR innovation and medicine will convey us one bit nearer to finding the undiscovered breakthroughs in life's journey. 


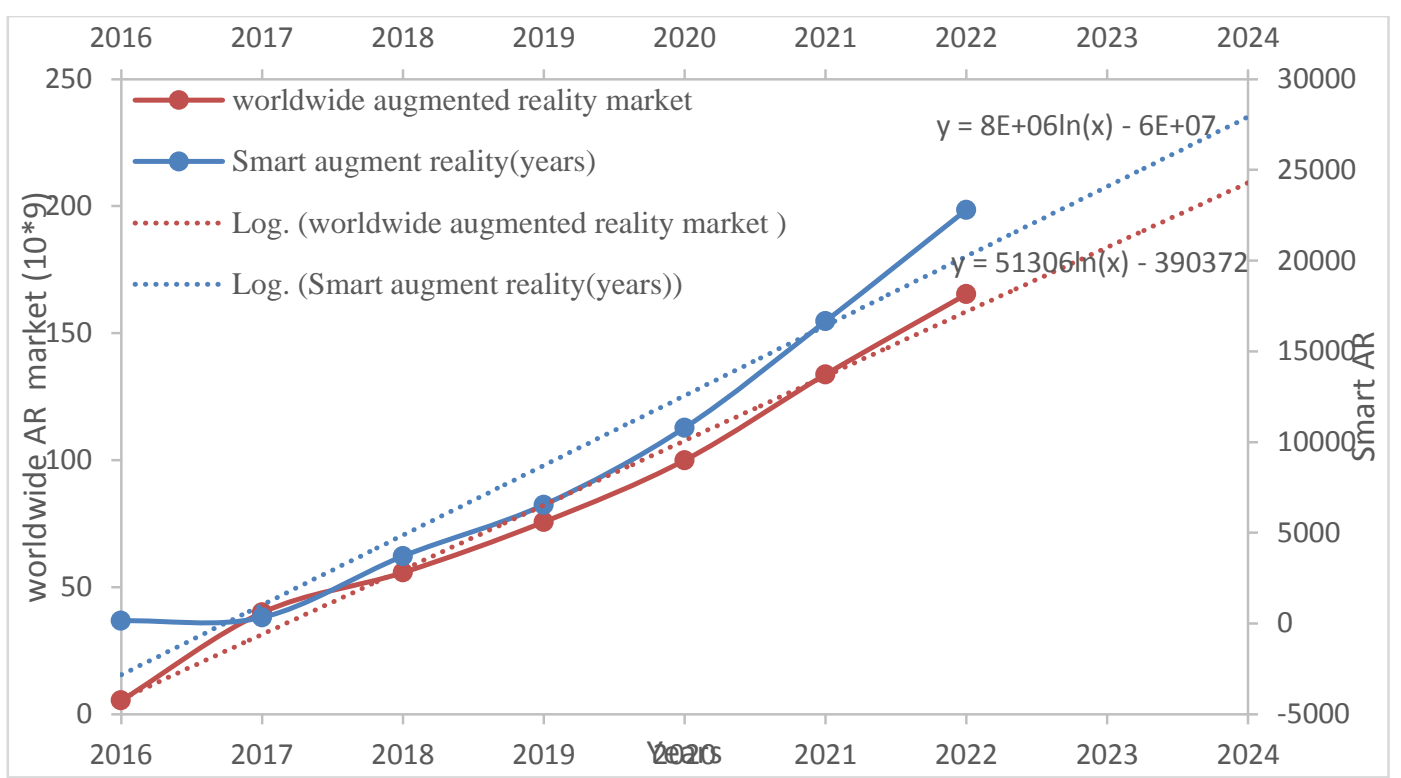

Figure 4.1:- Worldwide augmented reality market and Smart augmented reality glasses shipment form 2016-2024

According to [11-14], it is anticipated that the augmented reality income will be three times the VR in 2020. Comparison with 45.6 million AR hardware. According to Statista, the game is one of the sectors that most uses augmented reality. Games like PokemonGo have demonstrated the potential of augmented reality. By 2025, the user base of AR and VR games in the world is expected to reach 216 million users and worth $\$ 11.6$ billion.

\section{Limitations of $A R$ in education and medical field:-}

Various parts of AR innovation should be investigated, and many future research examinations stay to be directed in this moderately new territory. Various confinements exist in this innovation. For instance, as indicated [11,12], numerous members in an AR learning exercise concurred that the AR apparatuses are high, yet most members did not view the devices as powerful as perusing course books. They found that utilising AR instruments to acquire data was difficult. The reason may be that even though the AR device itself is anything but difficult to work, the methodology of sending the picture, perceiving the content and afterwards getting the significance of the material is tedious. This is because the innovation utilised the $3 \mathrm{G}$ system to associate with the Internet. In like manner, the members may need to trust that the data will be sent once more from the server $[14,15]$.

This limitation was also bolstered by a study done by [16] where the members revealed being disappointed when utilising the innovation outside and needed to fall back on approaching their educator for help. The outcomes demonstrated that even though the understudies experienced specific issues, they discovered advice, endured with the errand and connected viably in the extraordinary learning process. Despite the significant number of difficulties, the dimension of commitment in the outdoor AR exercises was still high [17]. As referenced before, the replication of concentrates identified with AR is developing quickly. The AR created demonstrates that members were excited for the potential of this innovation for sharing data and finding out about new ideas $[18,19]$.

Additionally, research ought to be directed to explore the most recent innovation called the portable mobile AR (MAR) framework, which is a smartphone application that is coordinated with the AR itself. This new type of AR innovation offers a learning knowledge that is connected to the formal classroom with the goal that to learn outside of class hours and outside of school limits [19-20]. The impediments expressed above, for the most part, features the issues encountered in AR to be technology related. Such items must be improved later with the end goal for AR to be generally accepted in learning. The first step to fix mobile AR was given when Google launched the Tango AR phone with Lenovo. This is not a primary device that mobile AR still needs to remove, but it shows the direction of the technology that Apple, Samsung and others can use to spur innovation and growth in the slowing smartphone market. Also, that is where the AR mobile's secret weapon comes in: the cycles of change. The more advanced mobile markets have reached saturation; Consumer sales are changing their phones regularly, although they do not need them. It is just something we do. However, this replacement cycle has been reduced from two to three years, 
and this is a major headache for Apple, Samsung and others. After nearly a decade of performance, Apple saw a drop in sales and revenue last year.

Some researchers [21-23] too indicated that their needs be upgrades in Internet portability to encourage client access to AR frameworks for learning. Expanded Internet access will give understudies the chance to utilise AR through a smartphone. This can make AR a ground-breaking learning device that can assist understudies with gaining content information and maintain that knowledge through their contact with the smartphone. It will likewise be more alarming if our health information is in the wrong hands and our administrations do not ensure our security and wellbeing. With a flicker of an eye, we could locate our future partner's health data before our eyes. If we neglect to make, institutionalise and pursue a proper set of principles concerning the treatment of one's health information. The world may turn into a place of dread where the poor, health-burdened and hereditarily- affected people are oppressed. Appropriate and auspicious guideline of the utilisation of information is paramount. So, we should stay mindful of the moral problems that accompany it.

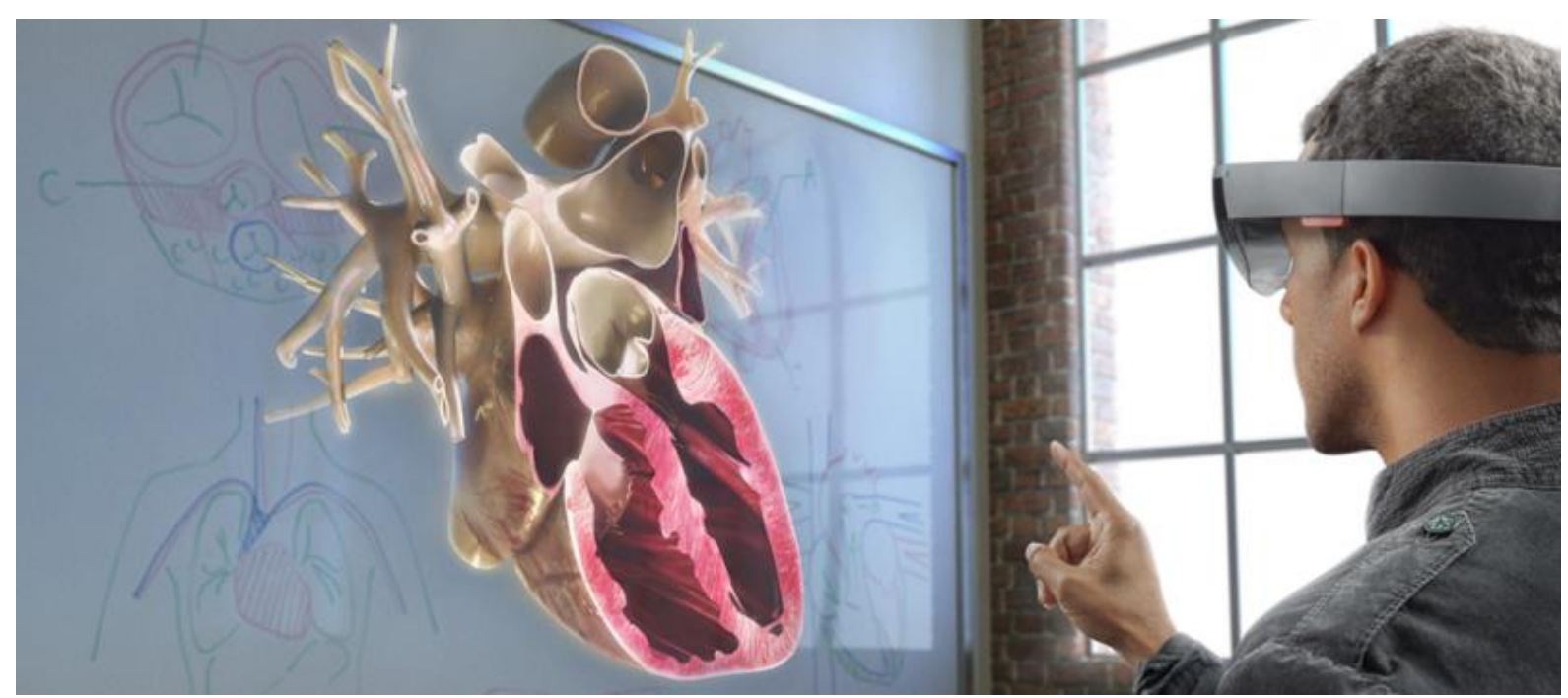

Plate 4.2:- Virtual reality three-dimension of heart description for cardiac study

\section{Conclusion:-}

This review of AR in education and medicine demonstrates that AR technology can be further developed. This is because the points of interest and valuable employments of AR highlights can draw in understudies in the learning process, help educators to expound well and make the understudies effectively comprehend what they are taught.

The utilisation of AR innovation has likewise gotten positive input from members and understudies who have demonstrated their enthusiasm for utilising AR in their learning processes. AR innovation still has a few constraints in education and medicine. Be that as it may, such confinements can be defeated through continuous research on the joining of AR in education and medicine is improved. At the point when the capability of AR advancements is all the more wholly investigated, the helpful capacities of AR can start to be utilised generally in the field of education and medicine for attaining a superior world.

\section{Reference:-}

1. TALK BUSINESS, The benefits of augmented reality in education and learning process. (2018) https://www.talk-business.co.u -and-learning-process/

2. Paresh Sagar, CEO of Excellent Web world, IoT, Web and Mobile App Development Company, The Impact of ARE. (2018) https://elearningucation-impact.

3. Bankole I. Oladapo, S. A., Zahedi, A. O. M. Adeoye, 3D printing of bone scaffolds with hybrid biomaterials, Composites Part B: Engineering, Volume 158, 1 February 2019, Pages 428-436

4. Rachel Bui, founder of Aires, an artificial intelligence lab and a co-founder of Australia - Vietnam Leadership Dialogue The future augmented reality in advanced medicine. (2017). https://www.oneyoungworld.com/ edicine. 
5. B. I. Oladapo, S. A. Zahedi, A. O. Awe, F. T. Omigbodun, V. A. Adebiyi, Analysis on corrosion resistant of electrodeposited ternary Co-WP alloy, Applied Surface Science 475, 627-632.

6. Michael Isberto, Blog Director colocation America, THE HISTORY OF AUGMENTED REALITY. (2018) https://www.coloented-reality. (Assessed may 2019)

7. How is Augmented Reality Used in Medicine? https://www.archer-soft.com/ey-used-medicine. (Assessed may 2019)

8. Bankole. I. Oladapo, S. Abolfazl Zahedi, Surya C. Chaluvadi, Satya S. Bollapalli, Muhammad Ismail, Model design of a superconducting quantum interference device of magnetic field sensors for magnetocardiography, Biomedical Signal Processing and Control, Vol. 46, Sept. 2018, Pages 116-120

9. Burton, E. P., Frazier, W., Annetta, L., Lamb, R., Cheng, R., \& Chmiel, M. Modelling Increased Reality Games with Preservice. Jl. of Technology and Teacher Education, (2011). 19(3), 303-329.

10. Hsu, J. L, Huang, Y. H. The Advent of Augmented-Learning: A Mixture of Augmented Reality and Cloud Computing. (2011).

11. Oladapo, B.I., Zahedi, S.A., Chong, S. Omigbodun,F.T., Malachi, I.O., 3D printing of surface characterisation and finite element analysis improvement of PEEK-HAP-GO in bone implant. Int J Adv Manuf Technol (2019) doi:10.1007/s00170-019-04618-w

12. Adeyinka O. M. Adeoye, Joseph F. Kayode, Bankole I. Oladapo, Samuel O. Afolabi, Experimental analysis and optimization of synthesized magnetic nanoparticles coated with PMAMPC-MNPs for bioengineering application, St. Petersburg Polytechnical University Journal: Physics and Mathematics, Volume 3, Issue 4, December 2017, Pages 333-338

13. Lamounier, E, Bucioli, A. Cardoso, A., Andrade, A. Soares, A. On the use of Augmented Reality techniques in education and clarification of cardiology data. AIC IEEE, 2010 (Vol. 1, pp. 2451-2454)

14. AccuVein over the dorsum of the hand. (Assessed March 17, 2019) https://www.justgiaccuveinforhomerton. (Assessed may 2019)

15. MICROSOFT HOLOLENS to advance the educational system and science(2015). https://www.engadget.comedical-student-demo/ (Assessed may 2019)

16. Bankole I. Oladapo, Adeyinka O. M. Adeoye, Muhammad Ismail, Analytical optimization of a nanoparticle of microstructural fused deposition of resins for additive manufacturing, Composites Part B: Engineering, Volume 150, 1 October 2018, Pages 248-254

17. Proximal- Long distance Surgery software. Available from Nazgoz, http://www.nazgoz.com/2016/09/proximielong-distance-surgery-software.html (Accessed March 17, 2019)

18. CliniCloud Mobile Medical Kit Combines Stethoscope, Contactless Thermometer in Tiny Package (L-R; a mobile featuring the app, the thermometer, and the stethoscope) 2015. https://www.medgadget.com/inesstethoscope-contactless-thermometer-in-tiny-package-video.html. (Assessed May 2019)

19. Bankole. I. Oladapo, S. A. Zahedi, F. V., O. M. Ikumapayi, M. U. Farooq. Three-dimensional finite element analysis of a porcelain crowned tooth, Beni-Suef University Journal of Basic and Applied Sciences, Volume 7, Issue 4, 2018, 461-464

20. JEREMY DIXON. Clinicloud connected stethoscope. Available from IPTC photo metadata. https://www.designboom.com/technology/clinicloud-connected-stethoscope-thermometer-medical-kit-02-132015/ (Accessed March 17, 2019)

21. Temitope Afolalu, Iyanuoluwa G. Akinwalere, Oluwaseun Olatoyea, Mayowa Oleseni, Chinonyerem Ehiemere, Evaluation of the Perspectives of Nursing Education on Global Health Nursing Competencies. IJMSCR, Volume 2, Issue 3; May-June 2019; Page No. 302-311.

22. P. Pratt, M. Ives, G. Lawton, J. Simmons, N. Radev, L. Spyropoulou, D. Amiras. Through the looking glass models with perforating vessels. Europ Radiology Exp, 2018; 2 (1) DOI: 10.1186/s41747-017-0033-2. 